\title{
Determination the Level of Physical Activity and Eating Behaviors of University Students
}

\author{
Serkan Düz ${ }^{1 \rtimes}$ \\ Sümeyye Tuba Aytekeli \\ 'Faculty of Sports Science, Inonu University, Turkey. \\ Email: serkan.duz@inonu.edu.tr Tel: +90422841061s \\ ${ }^{2}$ Institute of Health Sciences, Inonu University, Turkey. \\ Email:tubaladag@windowslive.com Tel:+905078649262
}

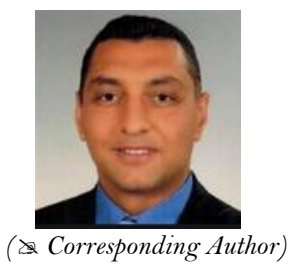

\begin{abstract}
The aim of this study was to determine the relationship between level of physical activity and eating behaviors of university students. 270 students attending to Inonu University in 2018-2019 academic year and volunteering were included in the study. A short form of the International Physical Activity Questionnaire (IPAQ-SF) and the Dutch Eating Behavior Questionnaire (DEBQ) were administered to the participants along with the socio-demographic information form. Data were analyzed by IBM statistics (SPSS, version 25.0, Armonk, NY) windows package program and independent samples t test, Kruskal Wallis H test and Mann-Whitney U test were used with descriptive statistics. The findings were evaluated at $95 \%$ confidence interval and $5 \%$ significance level. While there was no statistically significant difference between eating habits, departments, classes, monthly income and place of residence of university students, there was a significant difference between BMI, adequate and balanced nutritional status and the reasons for skipping meals. Moreover, there was no significant relationship between eating behaviors and physical activity levels of university students, but men were more physically active than women were. As a conclusion, the possible effects of mood on eating behavior and physical activity should be determined in more detail by face-to-face interviews with students who have high scores from DEBQ questionnaire. Moreover, awareness can be enhanced by organizing trainings and information meetings in order to gain healthy eating habits along with physical activity.
\end{abstract}

Keywords: Eating behavior, Physical activity, DEBQ, IPAQ-SF, University students, BMI.

Citation ! Serkan Düz; Sümeyye Tuba Aytekeli (2020). Determination the Level of Physical Activity and Eating Behaviors of University Students. Asian Journal of Education and Training, 6(1): 65-71. 6(1): $65-7$
History:

Received: 6 November 2019

Revised: 17 December 2019

Accepted: 20 January 2020

Published: 24 February 2020

Licensed: This work is licensed under a Creative Commons Attribution 3.0 License $(\boldsymbol{c c}) \boldsymbol{E}_{\mathbf{E}}$

Publisher: Asian Online Journal Publishing Group
Acknowledgement: All authors contributed to the conception and design of the study.

Funding: This study received no specific financial support.

Competing Interests: The authors declare that they have no conflict of interests.

Transparency: The authors confirm that the manuscript is an honest, accurate, and transparent account of the study was reported; that no vital features of the study have been omitted; and that any discrepancies from the study as planned have been explained.

Ethical: This study follows all ethical practices during writing.

\section{Contents}

1. Introduction

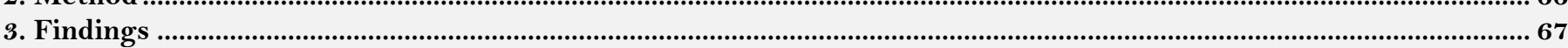

4. Discussion and Result .............

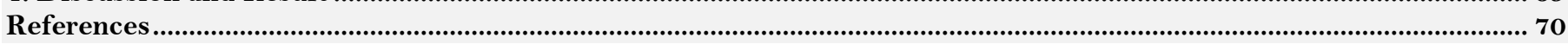




\section{Contribution of this paper to the literature}

This study contributes to the existing literature by examining the relationship between levels of physical activity and eating behaviors of university students.

\section{Introduction}

In recent years, eating problems have been increasing not only in societies with high levels of welfare but also in societies with low levels of welfare, thus inviting obesity and the health problems it brings with it GBD (2015); Centers for Disease Control and Prevention (2009). Because, the conveniences that the technology brings and the widespread of the modern lifestyle lead to rapid increase in prevalence of obesity in almost all countries globally. Another important reason for this increase in obesity prevalence is the adoption of a physically inactive lifestyle. The sedentary lifestyle is a well-known risk factor, especially for cardiovascular diseases (CVD) (British Medical Association Report, 2005). The World Health Organization (WHO) has already reported that approximately 6\% of deaths worldwide are due to physical inactivity and 5\% from obesity (WHO, 2005). Although it is known that physical activity (PA) decreases the prevalence of many chronic diseases such as cardiovascular, autoimmune and diabetes mellitus, today's modern lifestyle and the fast pace of life force people to live more sedentary lifestyle and reduce the level of FA day by day. This causes various diseases and health problems (BMA, 2005; WHO, 2005). In particular, the habit of immobility has become increasingly popular among the young population between the ages of 15-24, and begun to become a new lifestyle. Considering that $81 \%$ of the young population between the ages of 11 and 17 in the world are physically inactive, increasing the level of PA is very important for all age (WHO, 2013). For this reason, one of the most important problems of modern life is obesity caused by low physical activity and bad eating habits. These undesirable behaviors in lifestyle lead to an increase in body weight and obesity prevalence in both developed and developing countries (Arslan, 2014). There is a linear relationship between the degree of obesity and Type 2 diabetes, CVD, certain types of cancer, and even the risk of death. Therefore, adequate physical activity and good eating habits are thought to be important factors in preventing body weight control and obesity prevalence (Zimmerman and Snow, 2012).

The transition from high school to university is one of the most sensitive periods in the lives of young adults who face many different challenges. Because this transition period, where individuals gain individual independence and change their social environment by getting out of parental control is an important phase in which health behaviors related to eating habits and living conditions are affected. Therefore, healthy living habits generally leave their place to an unhealthy lifestyle in the first years of the university life (Bagordo et al., 2013). This unhealthy lifestyle leads to an increase in fast food consumption and a decrease in the consumption of fruit and vegetable (Denney-Wilson et al., 2009). Moreover, the new academic responsibilities and obligations encountered create stress on individuals and affect previous eating (Garipağaoğlu et al., 2012) and physical activity habits (Arıkan, 2015). All of these show themselves as an increase in the body weight of the students in the first years of the university (Turkish Demographic and Health Survey (TDHS), 2008). Furthermore, risky behaviors for the health such as physical inactivity, malnutrition, abuse of tobacco, tobacco products and alcohol are tried and become habitual in this period (Pekcan, 2006). When the literature was examined, despite the decrease in PA levels with the transition from high school to university (Pekcan and Karaagaoglu, 2000) it is seen that the PA habit gained in youth and adolescence is also effective for the rest of student's life (Hills et al., 2007).

Therefore, identifying the factors that cause freshman to undergo poor eating habits and inadequate PA, as well as changes in their lifestyle, is of great importance. Whereas, there are many studies reporting FA levels and eating habits of university students from different countries in the literature (Moreno-Gómez et al., 2012; Rodríguez et al., 2013; Kayode and Alabi, 2020; Tek et al., 2020) there are a limited number of studies investigating FA levels and eating habits of university students and related factors in our country (Korkmaz, 2010; Aksoydan and Cakır, 2011; Arslan. et al., 2016; Kargün et al., 2016). However, understanding eating habits and PA levels and determining the factors affecting them are important for taking effective measures to develop healthy eating habits and increase PA levels. Because the majority of young people who will become adults of the future acquire or develop risky behaviors that will endanger their health in this period. Therefore, the purpose of this study is to determine the relationship between eating habits and PA levels of freshman and sophomores at the beginning of university education.

\section{Method}

In this part of the study, information about the participant and the analysis of the data are presented.

\subsection{Model of the Study}

In this study, causal comparison model was used as it was aimed to compare the eating habits and PA levels of university students in terms of various variables. In the causal comparison model, it is aimed to compare the groups that differ in terms of a certain variable (Karasar, 2016).

\subsection{Population and Selection of Sample}

While the population of study was formed by approximately 8000 freshman and sophomores studying at Inonu University in the 2018-2019 academic year, the formula $\mathrm{Nt}^{2} \mathrm{pq} / \mathrm{d}^{2}(\mathrm{~N}-1)+\mathrm{t}^{2} \mathrm{pq}$ (Sümbüloğlu and Sümbüloğlu, 2009) was used to determine the sample group that will represent the population. With a $95 \%$ confidence interval and $5 \%$ sampling error, the sample size of the study was calculated to be at least 245 students, and accordingly, a questionnaire was applied to a group of 300 freshman and sophomores. Since 18 of the collected questionnaires contain incomplete and 12 of them include conflicting information, they were excluded from the study. As a result, the total of 270 students was included in the study and formed the sample. The descriptive characteristics of the participants are given in Table 1. 


\begin{tabular}{l|c|c|c|c|c}
\multicolumn{7}{l}{ Table-1. Descriptive characteristics of the participants. } \\
\hline Variable & $\mathbf{N}$ & $\overline{\mathbf{x}} \pm \mathbf{S D}$ & Min. & Max. \\
\hline \multirow{3}{*}{ Weight $(\mathrm{kg})$} & Woman & 106 & $57.80 \pm 10.08$ & 43 & 100 \\
\cline { 2 - 6 } & Male & 164 & $75.34 \pm 12.91$ & 50 & 120 \\
\cline { 2 - 6 } & Total & 270 & $68.52 \pm 14.59$ & 43 & 120 \\
\hline \multirow{3}{*}{ Height $(\mathrm{m})$} & Woman & 106 & $163.62 \pm 6.37$ & 145 & 190 \\
\cline { 2 - 6 } & Male & 164 & $177.91 \pm 6.43$ & 158 & 194 \\
\cline { 2 - 6 } & Total & 270 & $172.28 \pm 9.43$ & 145 & 194 \\
\hline \multirow{3}{*}{ BMI $\left(\mathrm{kg} / \mathrm{m}^{2}\right)$} & Woman & 106 & $21.56 \pm 3.38$ & 17.19 & 32.42 \\
\cline { 2 - 6 } & Male & 164 & $23.76 \pm 3.59$ & 17.45 & 36.11 \\
\cline { 2 - 6 } & Total & 270 & $22.92 \pm 3.65$ & 17.19 & 36.11 \\
\hline
\end{tabular}

Note: Mean \pm standard deviation, minimum and maximum values of 270 participants.

\subsection{Data Collection Tools}

In addition to the socio-demographic information form, International Physical Activity Questionnaire-Short Form (IPAQ-SF) and Dutch Eating Behavior Questionnaire (DEBQ) were used to determine the PA levels and eating behavior of the university students. International Physical Activity Questionnaire -Short Form (IPAQ-SF): IPAQ-SF consists of four different sections and seven questions and includes PA related questions that have been done for at least 10 minutes in the last 7 days. In the questionnaire, it is questioned that how many days and how long high intensity physical activity (HIPA), moderate intensity physical activity (MIPA) and walking (W) have been done in the last 7 days. In the last question, the time spent sitting or lying down, that is, without moving, is evaluated daily. The level of PA is calculated by using the MET method. One MET is equal to $3.5 \mathrm{ml} / \mathrm{kg} / \mathrm{min}$. This means that while resting, a person consumes $3.5 \mathrm{ml}$ of oxygen per minute in per $\mathrm{kg}$. In IPAQ-SF, it is expressed that 8.0 MET as HIPA, 4.0 MET as MIFA and 3.3 MET as W. The total amount of MET is calculated by determining how many days and how long each person does heavy, medium and low intensity PA. If any question in the questionnaire is answered as I do not know, the total MET value cannot be calculated. The level of PA is determined in three categories (Altun et al., 2005) such as;

Category I: Inactive ones: <600 MET min/week.

Category II: Minimum Active: 600-3000 MET min/week.

Category III: Sufficient level of PA for health: >3000 MET min/week.

Dutch Eating Behavior Questionnaire (DEBQ): DEBQ is a 33-item self-report questionnaire which consists of 3 subscales developed by Van Strien et al. (1986) It evaluate emotional eating behaviors (do you eat dessert when you are unhappy?), external eating behaviors (if the smell of what you eat is very nice, would you eat more than you normally eat?) and restrained eating behaviors (would you eat less than you want to eat to avoid getting fat?). The items in the questionnaire are evaluated with a 5-point Likert type scale which is ranging from 1 (never) to 5 (very often), with higher scores indicating greater endorsement of the eating behavior. Moreover, the option "irrelevant" is also offered for items. The psychometric properties of the DEBQ are strong. The subscale scores evidence good internal consistency across weight category groups. In a nonclinical sample of normal weight, overweight, and obese participants, coefficient alphas ranged from .92 to .94 for the DEBQ-restrained eating subscale, .96 to .97 for the DEBQ-emotional eating subscale, and .79 to .84 for DEBQ-external eating subscale (Bohrer et al., 2015). In general, the cut-off point was reported as 2.5 points in this scale. People who get above this score are considered to have emotional eating behavior. Anthropometric measurements: Body weights of the students were measured with a standard digital scale (Seca, Germany) that is sensitive to $0.05 \mathrm{~kg}$ with light clothes and without shoes. The height of the students was measured with a wall mounted standard meter (Mesilife MR200, Germany). Measurements were made when the feet were adjacent to each other, posterior of the body touching the wall and without shoes. Body mass index (BMI) of the students was calculated by the formula of dividing body weight $(\mathrm{kg})$ by the length of the square $\left(\mathrm{m}^{2}\right)$ and the results were classified according to the WHO reference values.

\subsection{Data Analysis}

The data obtained in the study were evaluated using the IBM statistics (SPSS version 25.0, Armonk, NY, USA) windows package program. The normality of the data was tested by Kolmogorov-Smirnov tests. While the independent sample t-test and one-way ANOVA test were used for comparing the mean values of the groups with normal distribution, the Mann-Whitney $\mathrm{U}$ test and Kruskal-Wallis $\mathrm{H}$ test were used to compare those did not show normal distribution. The results were evaluated in the $95 \%$ confidence interval and the significance level was $\mathrm{p}<.05$.

\section{Findings}

In this section, level of $\mathrm{PA}$ and eating habits of students were presented in details.

Monthly income of $34.4 \%$ of women was 0-500 TL, 38.4\% of men was 0-500 TL, 39.4\% of women was 500$1000 \mathrm{TL}, 35.4 \%$ of men $500-1000 \mathrm{TL}, 7.5 \%$ of women $1001-1500 \mathrm{TL}, 9.8 \%$ of men 1001-1500 TL, $8.5 \%$ of women $1501-2000 \mathrm{TL}, 4.9 \%$ of men $1501-2000 \mathrm{TL}, 6.6 \%$ of women $2001-2500 \mathrm{TL}, 4.3 \%$ of men $2001-2500 \mathrm{TL}, 10.4 \%$ of women $>2500 \mathrm{TL}, 7.3 \%$ of men $>2500 \mathrm{TL} ; 52.8 \%$ of women were freshman and $47.2 \%$ of them were sophomores, $76.8 \%$ of them were freshman, $23.2 \%$ were sophomores; It was determined that $34.9 \%$ of women received science education, $65.1 \%$ of social education, $47.6 \%$ of men received science education, and $52.4 \%$ of verbal education Table 2.

When Table 3 was examined, it was seen that $9.6 \%$ of the participants were underweight, $63.7 \%$ were normal weight (healthy), $22.2 \%$ were overweight and $4.4 \%$ were obese.

As seen in Table 4, mean scores of the restrained eating subscale of DEBQ was 3.09..75; emotional eating

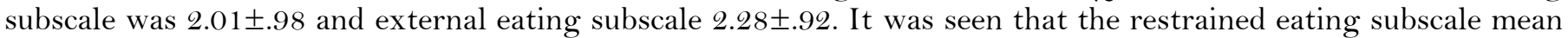
scores of the participants were higher than those of the emotional and external eating subscale. When the results were examined, it can be said that a restrictive tendency prevails in the eating behavior of the participants. 
Table-2. Sociodemographic characteristics of the participants.

\begin{tabular}{l|c|c|c|c|c}
\hline \multicolumn{1}{c}{ Table-2. Sociodemographic characteristics of the participants. } \\
\hline & Variable & \multicolumn{2}{|c|}{ Women } & \multicolumn{2}{c}{ Men } \\
\cline { 2 - 6 } & & $\mathrm{n}$ & $\%$ & $\mathrm{n}$ & $\%$ \\
\cline { 2 - 6 } & O-500 TL & 33 & 34.4 & 63 & 38.4 \\
\cline { 2 - 6 } Monthly income & $501-1000 \mathrm{TL}$ & 38 & 39.4 & 58 & 35.4 \\
\cline { 2 - 6 } & $1001-1500 \mathrm{TL}$ & 8 & 7.5 & 16 & 9.8 \\
\cline { 2 - 6 } & $1501-2000 \mathrm{TL}$ & 9 & 8.5 & 8 & 4.9 \\
\cline { 2 - 6 } & $2001-2500 \mathrm{TL}$ & 7 & 6.6 & 7 & 4.3 \\
\cline { 2 - 6 } & $>2501 \mathrm{TL}$ & 11 & 10.4 & 12 & 7.3 \\
\hline \multirow{4}{*}{ Grade } & Freshman & 56 & 52.8 & 126 & 76.8 \\
\cline { 2 - 6 } & Sophomores & 50 & 47.2 & 38 & 23.2 \\
\cline { 2 - 6 } & Total & 106 & 100 & 164 & 100 \\
\hline Department & Science & 37 & 34.9 & 78 & 47.6 \\
\cline { 2 - 6 } & Social & 69 & 65.1 & 86 & 52.4 \\
\cline { 2 - 6 } & Total & 106 & 100 & 164 & 100 \\
\hline
\end{tabular}

Note: Percentage distribution of 270 participants.

Table-3. BMI of the participants.

\begin{tabular}{l|c|c}
\hline Classification of BMI & $\mathbf{n}$ & $\mathbf{\%}$ \\
\hline Underweight & 26 & 9.6 \\
\hline Normal Weight (healthy) & 172 & 63.7 \\
\hline Overweight & 60 & 22.2 \\
\hline Obese & 12 & 4.4 \\
\hline Total & 270 & 100 \\
\hline
\end{tabular}

Note: Percentage distribution of the participants' BMI

Table-4. Distribution of DEBQ scores.

\begin{tabular}{l|c|c|c|c}
\hline Subscales & $\mathbf{N}$ & $\mathbf{x} \pm \mathbf{~ S D}$ & Min. & Maks. \\
\hline Restrained eating & 270 & $3.091 \pm .752$ & 1.0 & 5.0 \\
\hline Emotional eating & 270 & $2.012 \pm .985$ & 1.0 & 5.0 \\
\hline External eating & 270 & $2.286 \pm .929$ & 1.0 & 5.0 \\
\hline
\end{tabular}

Note: Mean \pm standard deviation, minimum and maximum values of DEBQ subscales.

Table-5. Comparison of BMI and DEBQ scores.

\begin{tabular}{|c|c|c|c|c|c|}
\hline \multirow{2}{*}{ Subscales } & Underweight & Normal & Overweight & Obese & \multirow{2}{*}{ p } \\
\hline & $\overline{\mathbf{x}} \pm \mathrm{SD}$ & $\overline{\mathbf{x}} \pm \mathrm{SD}$ & $\overline{\mathrm{x}} \pm \mathrm{SD}$ & $\overline{\mathrm{x}} \pm \mathrm{SD}$ & \\
\hline Restrained eating & $3.37 \pm .71$ & $3.04 \pm .72$ & $3.12 \pm .84$ & $2.99 \pm .77$ & .159 \\
\hline Emotional eating & $2.10 \pm 1.03$ & $1.94 \pm .92$ & $2.12 \pm 1.16$ & $2.32 \pm .98$ & .363 \\
\hline External eating & $1.74 \pm .63$ & $2.18 \pm .92$ & $2.69 \pm .91$ & $2.57 \pm .71$ & $.000^{*}$ \\
\hline
\end{tabular}

In Table 5, it was seen that there was no statistically significant difference between the restrained eating and Emotional eating subscales and BMI except the external eating subscale. According to the results of comparison made to evaluate which groups were different, it was seen that there was a significant difference between overweight and underweight, and normal and overweight groups in terms of external eating behaviors.

\begin{tabular}{l|c|c|c}
\multicolumn{4}{c}{ Table-6. Comparison of $\mathrm{DEBQ}$ scores and the gender. } \\
\hline \multirow{2}{*}{ Subscales } & $\mathbf{W o m e n}$ & $\mathbf{M e n}$ & \multirow{2}{*}{$\mathbf{p}$} \\
\cline { 2 - 3 } & $\overline{\mathbf{x} \pm \text { SD }}$ & $\overline{\mathbf{x} \pm \text { SD }}$ & \\
\hline Restrained eating & $3.06 \pm .70$ & $3.10 \pm .78$ & .947 \\
\hline Emotional eating & $2.32 \pm 1.12$ & $1.81 \pm .82$ & $.000^{*}$ \\
\hline External eating & $2.48 \pm .97$ & $2.15 \pm .87$ & $.004^{*}$ \\
\hline Note: ${ }^{*} \mathrm{p}<.05$.
\end{tabular}

Note: ${ }^{*} \mathrm{p}<.05$.

According to Table 6, it was found that there was a significant difference between the mean scores of the emotional and external eating subscales and gender of the participants. The mean scores of emotional and external eating subscales of women were higher than those of men.

Table-7. Comparison of DEBQ scores and adequate and balanced diet status.

\begin{tabular}{l|c|c|c}
\hline \multirow{2}{*}{ Subscales } & $\mathbf{W o m e n}$ & $\mathbf{M e n}$ & \multirow{2}{*}{$\mathbf{p}$} \\
\cline { 2 - 3 } & $\overline{\mathbf{x} \pm \text { SD }}$ & $\overline{\mathbf{x} \pm \text { SD }}$ & \\
\hline Restrained eating & $3.08 \pm .76$ & $3.09 \pm .74$ & .500 \\
\hline Emotional eating & $1.19 \pm .91$ & $2.04 \pm 1.04$ & .727 \\
\hline External eating & $2.40 \pm .93$ & $2.15 \pm .90$ & $.021^{*}$ \\
\hline Note: ${ }^{*} \mathrm{p}<.05$.
\end{tabular}

There was a significant difference was found between mean scores of external eating subscales and adequate and balanced nutrition of the participants. External eating scores of the participants who consumed an adequate and balanced diet were found higher than those did not Table 7. 
Table-8. Comparison of DEBQ scores and the most important reasons for meal skipping.

\begin{tabular}{l|c|c|c|c|c|c|c|c|c}
\hline \multirow{2}{*}{\begin{tabular}{l} 
Subscales \\
\cline { 2 - 11 }
\end{tabular}} & $\begin{array}{c}\text { Lack of } \\
\text { time }\end{array}$ & $\begin{array}{c}\text { Having } \\
\text { no habit }\end{array}$ & Anorexia & $\begin{array}{c}\text { Get up } \\
\text { late }\end{array}$ & $\begin{array}{c}\text { Preparation } \\
\text { problem }\end{array}$ & $\begin{array}{c}\text { Course } \\
\text { attendance }\end{array}$ & \multicolumn{4}{|c}{ Other } \\
\cline { 2 - 11 } & $\overline{\mathrm{x}} \pm \mathrm{SD}$ & $\overline{\mathrm{x} \pm \mathrm{SD}}$ & $\overline{\mathrm{x} \pm \mathrm{SD}}$ & $\overline{\mathrm{x} \pm \mathrm{SD}}$ & $\overline{\mathrm{x} \pm \mathrm{SD}}$ & $\overline{\mathrm{x} \pm \mathrm{SD}}$ & $\overline{\mathrm{x} \pm \mathrm{SD}}$ & $\mathrm{KW}$ & $\mathrm{p}$ \\
\hline Restrained eating & $.28 \pm .68^{\mathrm{a}}$ & $.99 \pm .7 \mathrm{O}^{\mathrm{a}, \mathrm{b}}$ & $2.89 \pm .65^{\mathrm{b}}$ & $.21 \pm .82$ & $.22 \pm .87$ & $.59 \pm .63$ & $.06 \pm .78$ & 4.751 & $.02^{*}$ \\
\hline Emotional eating & $.06 \pm .13$ & $.99 \pm .89$ & $.91 \pm .89$ & $.04 \pm .91$ & $.95 \pm .72$ & $.53 \pm .79$ & $.16 \pm .05$ & .564 & .363 \\
\hline External eating & $.13 \pm .90^{\mathrm{a}}$ & $.80 \pm .92^{\mathrm{a}}$ & $.06 \pm .89$ & $.24 \pm .91$ & $.88 \pm .94$ & $.25 \pm .91$ & $.01 \pm .75$ & 1.670 & $.001^{*}$ \\
\hline
\end{tabular}

Note: ${ }^{*} \mathrm{p}<.05$, a: significant difference between time and no habit; b: significant difference between the lack of appetite and no habit.

According to the results of Kruskal Wallis H-test conducted to determine whether there was a significant relationship among the restrained, emotional and external eating subscales in terms of the most important reasons for skipping meal. It was found that there was a significant difference between the means of restrained and external eating subscale Table 8. While the reason for skipping meals that differ significantly in the restrained eating subscale were lack of time, no habit of meal and anorexia, the reason for skipping meals in the external eating subscale was lack of time and having no habit of meal.

Table-9. Correlation between DEBO and MET scores of the participants.

\begin{tabular}{|c|c|c|c|}
\hline & & & MET \\
\hline \multirow{9}{*}{ Spearman's rho } & \multirow{3}{*}{ Restrained eating } & $\mathrm{r}$ & -.015 \\
\hline & & $\mathrm{p}$ & .810 \\
\hline & & $\mathrm{n}$ & 270 \\
\hline & \multirow{3}{*}{ Emotional eating } & $\mathrm{r}$ & -.025 \\
\hline & & $\mathrm{p}$ & .677 \\
\hline & & $\mathrm{n}$ & 270 \\
\hline & \multirow{3}{*}{ External eating } & $\mathrm{r}$ & -.018 \\
\hline & & $\mathrm{p}$ & .767 \\
\hline & & $\mathrm{n}$ & 270 \\
\hline
\end{tabular}

Note: Correlation was not significant at the .05 level (2-tailed).

Based on the Spearman correlation results, there was no significant relationship between the mean scores of restrictive, emotional and external eating subscales and MET Table 9.

Table-10. Comparison of MET scores and gender of participants

\begin{tabular}{|c|c|c|c|c|c|c|}
\hline MET & Gender & $\mathbf{N}$ & $\overline{\mathrm{x}} \pm \mathrm{SD}$ & Rank means & Mann-Whitney U & $\mathrm{p}$ \\
\hline \multirow{3}{*}{ Low } & Women & 106 & $433.03 \pm 197.91$ & 412.50 & \multirow{3}{*}{645.00} & \multirow{3}{*}{.808} \\
\hline & Men & 164 & $452.03 \pm 201.71$ & 412.50 & & \\
\hline & Total & 270 & $441.59 \pm 198.42$ & 412.50 & & \\
\hline \multirow{3}{*}{ Middle } & Women & 106 & $1131.97 \pm 532.65$ & 956.00 & \multirow{3}{*}{3.038 .00} & \multirow{3}{*}{.207} \\
\hline & Men & 164 & $1222.78 \pm 535.19$ & 1102.00 & & \\
\hline & Total & 270 & $1188.73 \pm 534.29$ & 1039.50 & & \\
\hline \multirow{3}{*}{ High } & Women & 106 & $3420.50 \pm 821.20$ & 3447.25 & \multirow{3}{*}{65.500} & \multirow{3}{*}{$.000^{*}$} \\
\hline & Men & 164 & $2503.26 \pm 656.62$ & 2426.00 & & \\
\hline & Total & 270 & $2698.41 \pm 783.17$ & 2532.50 & & \\
\hline \multirow{3}{*}{ Total } & Women & 106 & $1044.39 \pm 781.98$ & 799.25 & \multirow{3}{*}{645.20} & \multirow{3}{*}{$.000^{*}$} \\
\hline & Men & 164 & $1367.93 \pm 925.03$ & 1140.00 & & \\
\hline & Total & 270 & $1240.91 \pm 884.44$ & 966.75 & & \\
\hline
\end{tabular}

According to Table 10, there was a statistically significant mean difference in high and total MET groups. A significant difference was found between female and male in high and total MET group. While the mean of the MET scores of the women was higher than those of the men in high MET group, the mean of the MET scores of the men was higher than those of the women in total MET group.

\section{Discussion and Result}

The purpose of this study was to determine the relationship between level of physical activity and eating behaviors of university students. As a result of study, the fact that the weight average of women is lower than that of men reflects the world average. Moreover, when the mean of BMI were examined, it was seen that the mean of women was lower than those of male participants Table 1. The demographic data of the participants who participated in our study are in line with the TUIK report published in 2015. In the report, the value of mean weight and height of men in Turkey was reported to be higher than that of women (Turkish Statistics Institute, 2015).

When the monthly income of participant considered, it was found that monthly income of the women was higher than those of men. We can say that the cause of monthly income of the women was higher than those of men due to the more protectionist approach of families towards their girls. Since there is no study on this subject, it is not possible to quantitatively test and verify this inference. However, the reasons for these results can be investigated with future studies. It was also noted that female participants were mostly stayed with their families, whereas male participants stayed in the dormitory. This may significantly affect the eating habits of participants.

When the DEBQ scores of the participants evaluated, it was seen that the highest score belongs to emotional eating subscale. It is clear that the emotional eating behavior varies according to the type and severity of the emotion seen in the participants (Bozan, 2009). However, there was no statistically significant difference in the restrained and emotional eating subscales according to BMI of the participant, it was seen that there was a statistically significant difference in the external eating subscale. When the results of post-hoc test was examined, 
it was seen that difference was between overweight and underweight and normal and overweight groups. These findings were similar to the studies in the literature. Snoek et al. (2007) showed a positive relationship between obesity and external eating behavior. The higher emotional eating scores of the participants with the problem of overweight or obesity as well as restrained eating behaviors were consistent with the findings of Camacho et al. (1991). While changing emotional states have an effect that eliminates the restrained eating behavior, on the other hand, it is known that people who show emotional eating pattern can consume too much food (Van et al., 1987). Moreover, these findings are thought to coincide with the relationship between bulimia symptom levels and eating styles. According to the findings of the study, restrained, emotional and external eating subscales was significantly different from abnormal eating patterns and non-binge eating behavior.

BMI of most of the participants included in our study are in the normal range. Moreover, mean scores of restrained, emotional and external eating subscales of the participants with higher BMI are higher than those of lower BMI. Therefore, it is thought that the high emotional eating score does not cause obesity in the majority of the participants because of the high metabolic rate and physical activity of the young participants. Hwang et al. (2019) reported that physical activity increases metabolic rate and maintains body mass index within the normal range, similar to our findings. It was found that eating behaviors were not affected by the monthly income and residence status of the participants.

External eating scores of the participants who consumed an adequate and balanced diet were found higher than those did not. Because, adequate and balanced diet is a quite important factor that protects health, keeps the person away from diseases, provides physical and social peace, improves the body, energizes and increases success (Vural, $2015)$.

It was found that there was a significant difference between the means of restrained and external eating subscales in terms of the most important meal skipping reasons variable. The most important reason for skipping meal was lack of time and not having habit of meal a meal. Therefore, various measures can be taken to teach students how to use time efficiently and to gain regular eating habits.

There was no significant correlation between the subscales of DEBQ and MET scores. Thus, we can say that MET status of the participants do not affect the eating behaviors. In this study, there was a significant difference between the level of PA and different emotional states. In a study conducted by Dankel et al. (2016) they revealed that the individuals with sedentary lifestyle and obese had emotionally deteriorated. This finding shows the importance of the PA on emotional states. Camacho et al. (1991) showed that participants who have low levels of PA without depressive symptoms were at higher risk of depression than those with high PA levels. In a review by Mammen and Faulkner (2013) it was stated that increasing PA is a valuable strategy to improve mental health and reduce the risk of depression (Mammen and Faulkner, 2013). The number of studies reporting that promotion of physical activity which is important for public health is gradually increasing. Therefore, exercise programs should be a part of social health programs. It is also important to conduct new studies focusing on the relationship between lifestyle and mental state.

In the study, the mean of MET score of men was statistically higher than that of women Table 10. This shows that gender of students affects their MET scores. This finding is similar to the literature. According to the study conducted by Ergün (2013) the PA score of men was higher than that of women. Similarly, another study found MET scores of men higher than those of women (Genç et al., 2011). Finally, another study conducted in 2013 found that MET scores of men were higher than those of women (Almas et al., 2013). This may be due to the fact that male students spend most of time in the open area and engage in more physical activity than female. Although it was not statistically significant, the highest MET score was recorded in those who did regular breakfast. We can say that doing regular breakfast had effect on MET scores. But, Kara et al. (2017); Ozilbey (2013) and Yildirım (2010) were reported that regular meal consumption of students does not have a statistically significant effect on the level of PA. Therefore, we can say that participation in physical activity is not affected by doing regular breakfast.

According to the WHO report, the fact that obesity, which has reached the epidemic level worldwide (WHO, 2009) and has become a problem threatening the health of people, has an impact on the emergence of many health problems (Troop et al., 2002) which makes it necessary to conduct more studies in this field. Therefore, it is important to understand cause of physical inactivity and bad eating habits that will cause obesity and to examine in detailed with different dimensions. In this way, new suggestions can be made to improve healthy living conditions. In this study, it was found that overweight or obese participants showed more external eating behaviors compared to normal and underweight participant. Based on the results obtained from this, it can be said that the elements that initiate the eating behavior of an individual seeking a solution to weight problem or obesity should be specified in detail. When the literature on eating habits and physical activity is examined, it is seen that the eating problem is under the influence of environmental factors as well as genetic factors (Snoek et al., 2007). Extensive studies investigating the relationship between PA and eating behaviors in our country are very limited. For this reason, it is estimated that large-scale studies to evaluate the eating habits and PA level of the young population in our country will fill an important gap in the literature.

In the future studies, investigating the moods of the participants with high emotional, external and restrained eating behaviors can provide more detailed information about the eating behavior and PA of the individuals.

\section{References}

Aksoydan, E. and N. Cakır, 2011. Evaluation of nutritional behavior, physical activity level and body mass index of adolescents. Gulhane Medical Journal, 53(4): 264-270.

Almas, A., M. Islam and T.H. Jafar, 2013. School-based physical activity programme in preadolescent girls (9-11 years): A feasibility trial in karachi, pakistan. Archives of Disease in Childhood, 98(7): 515-519.Available at: https://doi.org/10.1136/archdischild-2012303242 .

Altun, B., M. Arici, G. Nergizoglu, U. Derici, O. Karatan, C. Turgan and S. Caglar, 2005. Prevalence, awareness, treatment and control of hypertension in Turkey (the PatenT study) in 2003. Journal of Hypertension, 23(10): 1817-1823.Available at: https://doi.org/10.1097/01.hjh.0000176789.89505.59.

Arıkan, Z.Y., 2015. Nutritional habits of university students: Example of dumlupınar university. Dumlupinar University, Kutahya. 
Arslan, M., 2014. The investigation of the nutritional habits and physical activity habits of faculty members working at marmara university haydarpaşa campus. Marmara University, Istanbul.

Arslan., S.A., A. Daşkapan and B. Cakır, 2016. Determination of nutrition and physical activity habits of university students. TAF Preventive Medicine Bulletin, 15(3): 171-180.

Bagordo, F., T. Grassi, F. Serio, A. Idolo and A. De Donno, 2013. Dietary habits and health among university students living at or away from home in southern Italy. Journal of Food \& Nutrition Research, 52(3): 164-171.

Bohrer, B.K., K.T. Forbush and T.K. Hunt, 2015. Are common measures of dietary restraint and disinhibited eating reliable and valid in obese persons? Appetite, 87: 344-351.Available at: https://doi.org/10.1016/j.appet.2014.12.226.

Bozan, N., 2009. Testing the validity and reliability of the dutch eating behavior (debq) survey among turkish university students. Health sciences institute, department of nutrition and dietetics. Ankara: Başkent University.

British Medical Association Report, 2005. Preventing childhood obesity. London: BMA.

Camacho, T.C., R.E. Roberts, N.B. Lazarus, G.A. Kaplan and R.D. Cohen, 1991. Physical activity and depression: Evidence from the alameda county study. American Journal of Epidemiology, 134(2): 220-231.Available at: https://doi.org/10.1093/oxfordjournals.aje.a1 16074.

Centers for Disease Control and Prevention, 2009. Recommended community strategies and measurements to prevent obesity in the united states. MMWR, 58(RR-7): 1-23.

Dankel, S.J., J.P. Loenneke and P.D. Loprinzi, 2016. Mild depressive symptoms among americans in relation to physical activity, current overweight/obesity, and self-reported history of overweight/obesity. International Journal of Behavioral Medicine, 23(5): 553560.Available at: https://doi.org/10.1007/s12529-016-9541-3.

Denney-Wilson, E., D. Crawford, T. Dobbins, L. Hardy and A.D. Okely, 2009. Influences on consumption of soft drinks and fast foods in adolescents. Asia Pacific Journal of Clinical Nutrition, 18(3): 447-452.

Ergün, S., 2013. The relationship between enjoying exercise and physical activity in school age children. Marmara University, Istanbul.

Garipağaoğlu, M., B. Eliuz, K. Esin, P. Cagatay, H. Nalbant and Z. Solakoglu, 2012. Evaluation of nutritional status of first-year medical students. Istanbul Medical Journal, 13(1): 1-8.

GBD, 2015. Risk factors collaborators, 2016. Global, regional, and national comparative risk assessment of 79 behavioural, environmental and occupational, and metabolic risks or clusters of risks, 1990-2015: A systematic analysis for the global burden of disease study 2015. Lancet, 388(10053): 1659-1724.Available at: https://doi.org/10.1016/So140-6736(16)31679-8.

Genç, A., U. Şener, H. Karabacak and K. Uçok, 2011. Investigation of the differences in physical activity and quality of life between male and female young adults. Kocatepe Medical Journal, 12(3): 145-150.

Hills, A.P., N.A. King and T.P. Armstrong, 2007. The contribution of physical activity and sedentary behaviours to the growth and development of children and adolescents. Sports Medicine, 37(6): 533-545.Available at: https://doi.org/10.2165/00007256$200737060-00006$.

Hwang, H., W.-S. Jung, J. Kim, H.-Y. Park and K. Lim, 2019. Comparison of association between physical activity and resting metabolic rate in young and middle-aged Korean adults. Journal of Exercise Nutrition \& Biochemistry, 23(2): 16-21.Available at: https://doi.org/10.20463/jenb.2019.0012.

Kara, G.M., M. Güllü and S. Düz, 2017. Physical activity levels and obesity awareness status of secondary school students. Ankara: Gece Academy.

Karasar, N., 2016. Scientific research method: Concepts principles techniques. Ankara: Nobel.

Kargün, M., O. Togo, M. Biner and A. Pala, 2016. Investigation of physical activity levels of university students. Marmara University Journal of Sports Sciences, 1(1): 61-72.

Kayode, O.O. and Q.K. Alabi, 2020. Food consumption patterns, physical activity and over-weight and obesity among undergraduates of a private university in Nigeria. Clinical Nutrition Experimental: 1-7.Available at: https://doi.org/10.1016/j.yclnex.2020.01.00.

Korkmaz, N.H., 2010. Examination of Uludag University students' sports and nutrition habits. Journal of Uludağ University Faculty of Education, 23(2): 399-413.

Mammen, G. and G. Faulkner, 2013. Physical activity and the prevention of depression: A systematic review of prospective studies. American Journal of Preventive Medicine, 45(5): 649-657.Available at: https://doi.org/10.1016/j.amepre.2013.08.001.

Moreno-Gómez, C., D. Romaguera-Bosch, P. Tauler-Riera, M. Bennasar-Veny, J. Pericas-Beltran, S. Martinez-Andreu and A. Aguilo-Pons, 2012. Clustering of lifestyle factors in Spanish university students: The relationship between smoking, alcohol consumption, physical activity and diet quality. Public Health Nutrition, 15(11): 2131-2139.Available at: https://doi.org/10.1017/s1368980012000080.

Ozilbey, P., 2013. Determination of obesity prevalence and investigation of nutritional habits of primary school 1st level students. Dokuz Eylül University, Izmir.

Pekcan, G., 2006. Food and nutrition policies: What's being done in Turkey. Public Health Nutrition, 9(1a): 158-162.Available at: https://doi.org/10.1079/phn2005939.

Pekcan, G. and N. Karaagaoglu, 2000. State of nutrition in Turkey. Nutrition and Health, 14(1): 41-52.Available at: https://doi.org/10.1177/026010600001400105.

Rodríguez, F., X. Palma, A. Romo, D. Escobar, B. Aragú, L. Espinoza and J. Gálvez, 2013. Eating habits, physical activity and socioeconomic level in university students of Chile. Nutricion Hospitalaria, 28(2): 447-455.

Snoek, H.M., T. Van Strien, J.M. Janssens and R.C. Engels, 2007. Emotional, external, restrained eating and overweight in dutch adolescents. Scandinavian Jurnal of Psychology, 48(1): 23-32.Available at: https://doi.org/10.1111/j.1467-9450.2006.00568.x.

Sümbüloğlu, K. and V. Sümbüloğlu, 2009. Biostatistics. Ankara: Hatipoğlu Press.

Tek, N.A., H. Mortaş, S. Arslan, T. Tatar and S. Köse, 2020. The physical activity level is low in young adults: A pilot study from Turkey. American Journal of Public Health, 8(1): 7-13.

Troop, N.A., J.L. Treasure and L. Serpell, 2002. Further exploration of disgust in eating disorders. European Eating Disorders Review, 10(3): 218-226.Available at: https://doi.org/https://doi.org/10.1002/erv.444.

Turkish Demographic and Health Survey (TDHS), 2008. Hacettepe university. Ankara, Turkey: Institute of Population Studies/Ministry of Health.

Turkish Statistics Institute, 2015. Statistics with turkey. Ankara: TSI Press.

Van, S.T., J.E. Frijters, G.P. Bergers and P.B. Defares, 1987. The dutch eating behavior questionnaire for assessment of restrained, emotional, and external eating behavior. International Journal of Eating Disorders, 5: 295-315.

Van Strien, T., J.E.R. Frijters, G.P.A. Bergers and P.B. Defares, 1986. The dutch eating behavior questionnaire (DEBQ) for assessment of restrained, emotional, and external eating behavior. International Journal of Eating Disorders, 5(2): 295-315.Available at: https://doi.org/10.1002/1098-108x(198602)5:2<295::aid-eat2260050209>3.0.co;2-t.

Vural, O., 2015. Relationship between physical activity level and quality of life in desk workers. Gazi University, Ankara.

WHO, 2005. Preventing chronic diseases: A vital investment: Who global report. Genava: WHO Press.

WHO, 2009. Obesity preventing and managing the global epidemic report of a who consultation- who. Technical Report Series, Geneva: WHO Press.

WHO, 2013. Global action plan for the prevention and control of noncommunicable diseases 2013-2020. Geneva: WHO Press.

Yildirım, B., 2010. Investigation of obesity frequency and affecting factors in secondary school students in elazig city center. Firat University, Elazig.

Zimmerman, M. and B. Snow, 2012. An introduction to nutrition. CA, USA: Creative Commons. 